J. Lake Sci. (湖泊科学), 2018, 30(6): 1537-1551

DOI 10. 18307/2018. 0606

(c) 2018 by Journal of Lake Sciences

\title{
白洋淀沉积物氮磷赋存特征及其内源负荷
}

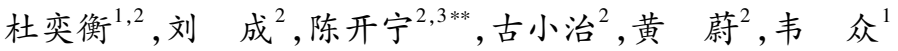 \\ ( 1 : 安徽农业大学动物科技学院, 合肥 230036) \\ (2: 中国科学院南京地理与湖泊研究所, 湖泊与环境国家重点实验室,南京 210008) \\ (3: 江苏高校水处理技术与材料协同创新中心,苏州 215009)
}

\begin{abstract}
摘 要: 白洋淀环境整治对区域生态文明建设具有重要意义, 然而, 目前对加剧白洋淀富营养化的内源氮、磷污染负荷依 然缺乏系统的研究. 本研究以野外调研和室内培养实验相结合形式, 在白洋淀主要水域内采集原位柱状沉积物样品, 详 细地研究了白洋淀沉积物中氮、磷赋存形态、间隙水中氮、磷剖面特征以及沉积物一水界面氮、磷交换特征. 结果表明, 白 洋淀沉积物总氮、总磷含量分别为 $1230.8 \sim 9559.0 \mathrm{mg} / \mathrm{kg}$ (均值 $2379.5 \mathrm{mg} / \mathrm{kg}$ ) 和 $344.4 \sim 915.4 \mathrm{mg} / \mathrm{kg}$ (均值 $608.4 \mathrm{mg} / \mathrm{kg}$ ), 氮、 磷累积污染量大. 沉积物中铵态氮赋存量大 $(3.2 \sim 175.8 \mathrm{mg} / \mathrm{kg})$, 由此导致间隙水中铵态氮浓度较高, 最高达到 $28.8 \mathrm{mg} / \mathrm{L}$. 沉积物磷形态以 Ca-P 和 Fe-P 为主, 分别占总量的 $38.3 \% \sim 76.1 \%$ 和 $3.98 \% \sim 18.0 \%$, 间隙水中磷酸盐浓度已接近甚至高于 国内外典型富营养湖区. 间隙水中高浓度的铵态氮和磷酸盐导致沉积物一水界面氮、磷交换通量较高, 铵态氮平均释放和 扩散通量分别为 106.37 和 $12.42 \mathrm{mg} /\left(\mathrm{m}^{2} \cdot \mathrm{d}\right)$; 磷酸盐平均释放和扩散通量分别为 15.06 和 $2.33 \mathrm{mg} /\left(\mathrm{m}^{2} \cdot \mathrm{d}\right)$, 沉积物内源 氮、磷污染负荷较高, 已严重威胁到白洋淀水环境质量, 迫切需要整治. 其中, 北部河口区域以及中部府河人湖区和人口 密集活动区沉积物氮、磷内源负荷尤为突出,应成为白洋淀沉积物内源污染整治的关键区域.
\end{abstract}

关键词: 白洋淀;沉积物一水界面;间隙水; 扩散通量; 释放通量

\section{Occurrence and internal loadings of nitrogen and phosphorus in the sediment of Lake Baiyangdian}

\author{
DU Yiheng ${ }^{1,2}$, LIU Cheng ${ }^{2}$, CHEN Kaining ${ }^{2,3 * *}$, GU Xiaozhi ${ }^{2}$, HUANG Wei ${ }^{2}$ \& WEI Zhong \\ (1: College of Animal Science and Technology, Anhui Agricultural University, Hefei 230036, P.R.China) \\ (2: State Key Laboratory of Lake Science and Environment, Nanjing Institute of Geography and Limnology, Chinese Academic \\ of Sciences, Nanjing 210008, P.R.China) \\ (3: Collaborative Innovation Center of Water Treatment Technology \& Material, Suzhou 215009, P.R.China)
}

\begin{abstract}
The environmental restoration of Lake Baiyangdian is of great significance for regional construction of ecological civilization. However, information on the internal loadings of nitrogen and phosphorus, which aggravated the eutrophic status of Lake Baiyangdian, is still limited. In this study, a detailed field survey was carried out to investigate the occurrence and fractions of nitrogen and phosphorus in the sediment, the profiles of nitrogen and phosphorus in interstitial water, and the exchanges of nitrogen and phosphorus across the sediment-water interface. A series of in situ sediment core samples were collected in important water areas of Lake Baiyangdian for the study. Results showed that the contents of total nitrogen and total phosphorus in the sediments were in the range of 1230.8-9559.0 mg/kg (average: $2379.5 \mathrm{mg} / \mathrm{kg}$ ) and $344.4-915.4 \mathrm{mg} / \mathrm{kg}$ (average: $608.4 \mathrm{mg} / \mathrm{kg}$ ), respectively. A large quantity of the cumulative pollution of nitrogen and phosphorus was discovered. The high levels of ammonium nitrogen in the sediments $(3.2-175.8 \mathrm{mg} / \mathrm{kg})$ led to high concentrations of ammonium nitrogen in the interstitial water, with the highest concentration of $28.8 \mathrm{mg} / \mathrm{L}$. The phosphorus forms in the sediments were largely Ca-P and Fe-P, accounting for $38.3 \%-76.1 \%$ and $3.98 \%-18.0 \%$, respectively. The phosphate concentrations in the interstitial water were close to or even higher than those in typi-
\end{abstract}

* 国家自然科学基金项目(41703078)、南京科技计划项目(2017sb310016) 和江苏省太湖水环境综合治理科研课题 ( TH2016401) 联合资助. 2018-03-26 收稿; 2018-05-07 收修改稿. 杜奕衡 (1994 ), 女, 硕士研究生; E-mail: duyiheng0510@163.com.

** 通信作者;E-mail :knchen@ niglas.ac.cn. 
cal eutrophic lakes around the world. The high levels of ammonium nitrogen and phosphate in the interstitial water resulted in high exchange fluxes of nitrogen and phosphorus across the sediment-water interface. The average release and diffusive fluxes of ammonium nitrogen were $106.37 \mathrm{mg} /\left(\mathrm{m}^{2} \cdot \mathrm{d}\right)$ and $12.42 \mathrm{mg} /\left(\mathrm{m}^{2} \cdot \mathrm{d}\right)$, respectively. The average release and diffusive fluxes of phosphate were $15.06 \mathrm{mg} /\left(\mathrm{m}^{2} \cdot \mathrm{d}\right)$ and $2.33 \mathrm{mg} /\left(\mathrm{m}^{2} \cdot \mathrm{d}\right)$, respectively. The high internal loadings of nitrogen and phosphorus in the sediments are now serious threat to the water environmental quality of Lake Baiyangdian. Urgent measures should be carried out to reduce the internal loadings. Especially, the northern estuary area and the central heavily populated area under the influence of the Fuhe River had higher internal loadings of nitrogen and phosphorus than other areas. These two areas should be given top priority during the remediation of internal loadings in Lake Baiyangdian.

Keywords: Lake Baiyangdian; sediment-water interface; pore-water; diffusive flux; release flux

富营养化是湖泊发展过程中面临的主要生态灾害之一. 大量外源污染物持续不断地进人湖泊, 在湖泊 中积聚并超过其天然自净能力, 是导致湖泊富营养化的直接原因. 氮、磷被认为是导致湖泊及其他水体富营 养化的主要生源要素. 大量研究表明 ${ }^{[1]}$, 富营养化的发生同时受到了氮、磷的影响和限制. 随着湖泊富营养 化的发展, 水体中氮、磷营养盐不断累积, 并通过沉降、扩散等形式汇人沉积物中, 使得沉积物成为湖泊水体 中氮、磷的重要蓄积库 ${ }^{[2]}$. 当沉积物中氮、磷累积至一定程度时, 可在风浪扰动、底栖扰动、氧化还原环境改 变等条件下, 通过扩散、对流、再悬浮等形式不断向上覆水体释放, 成为湖泊的内源污染 ${ }^{[3-5]}$. 诸多富营养化 湖泊整治经验表明, 在沉积物内源氮、磷负荷未得到有效削减前, 即使切断了外源污染负荷, 湖泊依然可能 在数年甚至数十年内呈现富营养化状态 ${ }^{[6-8]}$. 因此, 湖泊沉积物氮磷赋存及其内源负荷的研究对于湖泊富营 养化整治具有重要意义.

白洋淀 $\left(38^{\circ} 43^{\prime} \sim 39^{\circ} 02^{\prime} \mathrm{N}, 115^{\circ} 38^{\prime} \sim 116^{\circ} 07^{\prime} \mathrm{E}\right.$ ) 位于河北省中部, 总面积为 $366 \mathrm{~km}^{2}$, 流域面积为 31200 $\mathrm{km}^{2[9]}$, 是华北地区最大的浅水湖泊 ${ }^{[10]}$. 随着雄安新区的成立及其长远规划的需求, 白洋淀作为新区内最重 要的水域之一, 其生态环境状况受到各界的广泛关注. 然而, 流域内长期以来快速的经济、社会发展所产生 的各类工农业及生活污染不断汇人白洋淀水域,使得白洋淀受到了严重的污染, 水体已呈现严重的富营养 化状态 ${ }^{[1-12]}$. 早在 $1990 \mathrm{~s}$, 白洋淀已经成为典型的富营养化湖泊 ${ }^{[13]}$, 多年来富营养化状况不断加剧, 已成为 区域内生态文明发展的重要制约因素. 因此, 白洋淀富营养化整治及环境修复对区域发展具有重要现实意 义. 在此过程中,对白洋淀各类污染负荷的研究将为其生态环境整治提供重要理论及技术支撑.

已有研究表明 ${ }^{[14]}$, 除了长期接纳来自保定市生活污水和工业废水的府河仍不断流人白洋淀, 其他人淀 河流流量已逐渐减少, 多条河流已出现长期季节性断流现象. 在此背景下, 白洋淀内源氮、磷负荷已成为加 剧白洋淀富营养化的重要污染源. 然而, 目前对于白洋淀的研究主要关注水相及水生植被层面, 如对白洋淀 水体理化特性及污染情况 ${ }^{[15]}$ 、植被分布情况 ${ }^{[16]}$ 等的研究. 少量研究曾对白洋淀部分区域沉积物总氮、总 磷 ${ }^{[17]}$ 和金属 ${ }^{[18]}$ 及持久性有机污染物 ${ }^{[19]}$ 状况进行研究. 已有研究虽然为白洋淀污染负荷研究提供了一定的 支撑, 但目前对于全淀范围内底泥氮、磷详细赋存状况及沉积物一水界面氮、磷交换通量的研究较少, 无法满 足白洋淀生态环境整治过程中对沉积物内源氮、磷污染负荷的整治需求. 因此, 本研究在白洋淀重要水域内 布设了多个研究点位, 以野外原位调研和室内培养实验相结合的形式对白洋淀沉积物氮、磷赋存含量、形态 及沉积物一水界面氮、磷交换情况进行详细地研究, 希望通过此研究提供更加详实的白洋淀沉积物内源氮、 磷负荷数据, 为白洋淀沉积物内源污染整治提供科学的依据.

\section{1 材料与方法}

\section{1 研究区域与样品采集}

白洋淀污染整治已成为雄安新区建设过程中需要解决的重要生态环境问题, 其中, 沉积物内源污染负 荷的削减是淀区生态环境恢复的关键. 为了调研白洋淀沉积物氮、磷营养盐赋存及其内源负荷状况, 于 2017 年 5 月在白洋淀水域内共设置了 11 个采样点位. 由于白洋淀水陆交错, 淀内环境复杂, 因而采样点位主要 围绕重要水道和水域面积相对较大的淀. 使用柱状重力采样器 ( $\Phi 90 \mathrm{~mm} \times 500 \mathrm{~mm}$, Rigo 公司, 日本) 原位 采集柱状沉积物样品 22 根, 具体采样点位分布状况如图 1 所示. 各柱状沉积物样品深度均在 $20 \sim 30 \mathrm{~cm}$ 之 间, 在无扰动情况下, 将所有柱状样品运至实验室内, 确保沉积物一水界面处于接近原位环境的状态. 同时, 
每个点位采集 $5 \mathrm{~L}$ 上覆水用于沉积物氮、磷静态释放实验. 沉积物柱状样品运回实验室后立即放置于流动培 养装置内,在与原位温度相近的条件下进行沉积物一水界面氮、磷交换通量的研究.

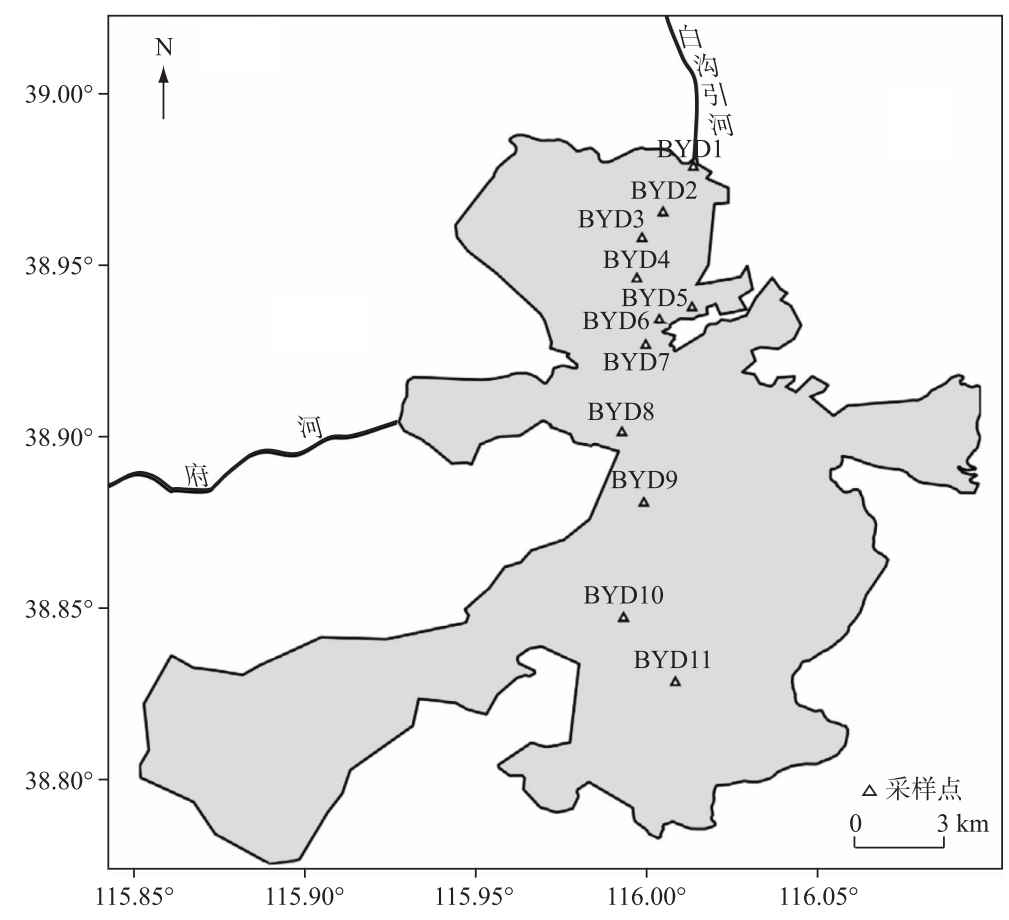

图 1 白洋淀底泥柱样采集点位分布

Fig. 1 Distribution of the sediment core sampling sites in Lake Baiyangdian

\section{2 界面通量研究方法}

1.2.1 实验方法 1) 静态释放实验: 所有柱状样品转运至实验室后, 立即使用 400 目 $(0.038 \mathrm{~mm})$ 篎绢过滤原 位采集的上覆水样, 以去除水样中 $40 \mu \mathrm{m}$ 粒径以上的颗粒物及一些浮游动物, 以避免对柱样内水柱和泥水 界面的扰动, 便于开展静态释放培养实验. 所有样品按照编号顺序整齐排列, 以便进行下一步实验. 采用虹 吸的方法, 使用乳胶管引流排出柱状泥样的上覆水, 避免摚动沉积物一水界面, 随后沿壁缓慢加人过滤后的 水样至界面以上 $20 \mathrm{~cm}$ 处并做标记. 释放实验开始后每隔 $12 \mathrm{~h}$ (取至 $72 \mathrm{~h}$ ) 在上覆水中部抽取 $50 \mathrm{ml}$ 水样,使 用 $0.45 \mu \mathrm{m}$ 水系膜过滤并检测水样中的铵态氮及磷酸盐, 取样后添加原水样至 $20 \mathrm{~cm}$ 刻度线标记处.

2) 间隙水获取方法: 间隙水的获取使用平衡式间隙水获取装置 (Peeper) 完成. 每个 Peeper 含有 30 个小 格, 格间距 $4 \mathrm{~mm}$, 每格容量为 $300 \mu \mathrm{l}$. 使用前将孔径 $0.45 \mu \mathrm{m}$ 的硝酸纤维滤膜固定于 Peeper 两侧, 置于去离 子水中充氮气 $24 \mathrm{~h}$ 以排出 Peeper 内的氧. 随后, 将 Peeper 插人至柱状沉积物中, 沉积物一水界面上部露出约 $3 \sim 5 \mathrm{~cm}$, 以此获得完整的间隙水一上覆水剖面. 将柱样置于室温下平衡 $3 \mathrm{~d}$ 后, 取出 Peeper 并使用无氧去离 子水冲洗, 之后使用酶标板取出 Peeper 内平衡的间隙水样. 在酶标仪 (Biotek Epoch, Winooski, VT, USA) 中 采用微量比色法检测间隙水中铵态氮和磷酸盐浓度 ${ }^{[20]}$.

1.2.2 释放及扩散通量计算 沉积物一水界面氮、磷扩散通量计算使用以下公式:

$$
F=\varphi \cdot D_{s} \frac{\mathrm{d} C}{\mathrm{~d} z}
$$

式中, $F$ 代表铵态氮、磷酸盐的扩散通量 $\left(\mathrm{mg} /\left(\mathrm{m}^{2} \cdot \mathrm{d}\right)\right)$, 通量正值表示污染物由底泥向上覆水体中释放, 负 值表示污染物由上覆水体向底泥中汇人; $\varphi$ 代表底泥 $(0 \sim 3 \mathrm{~cm})$ 的孔隙度; $D_{s}$ 代表铵态氮或磷酸盐在泥水界 面处的扩散系数 $\left(10^{-6} /\left(\mathrm{cm}^{2} \cdot \mathrm{s}\right)\right.$ ), 可根据底泥的孔隙度 $\varphi$ 计算 (当 $\varphi<0.7$ 时, $D_{s}=\varphi \cdot D_{0}$; 当 $\varphi>0.7$ 时, $D_{s}=$ $\left.\varphi^{2} \cdot D_{0}\right)^{[21]} ; D_{0}$ 代表铵态氮或磷酸盐在泥水界面处的理想扩散系数 $\left(10^{-6} /\left(\mathrm{cm}^{2} \cdot \mathrm{s}\right)\right)$, 可根据界面温度计 
算 ${ }^{[22]} ; \mathrm{d} C / \mathrm{d} z$ 代表铵态氮或磷酸盐在泥水界面处的浓度梯度, 本研究中使用界面上部 $3.2 \mathrm{~cm}$ 的上覆水体和 下部 $3.2 \mathrm{~cm}$ 底泥之间的浓度梯度, 在计算过程中使用一级反应动力学进行拟合 ${ }^{[23]}$.

沉积物中氮、磷释放通量的计算公式为 ${ }^{[23]}$ :

$$
r=\left[V\left(C_{n}-C_{0}\right)+\sum_{n-1}^{n} V_{j-1}\left(C_{j-1}-C_{\mathrm{a}}\right)\right] /(A \cdot t)
$$

式中, $r$ 为释放通量 $\left(\mathrm{mg} /\left(\mathrm{m}^{2} \cdot \mathrm{d}\right)\right) ; V$ 为上覆水体积 $(\mathrm{L}) ; C_{n} 、 C_{0}$ 和 $C_{j-1}$ 分别为第 $n$ 次、初始和第 $j-1$ 次采样时 铵态氮或磷酸盐的浓度 $(\mathrm{mg} / \mathrm{L}) ; C_{\mathrm{a}}$ 为水样中所添加物质的浓度 $(\mathrm{mg} / \mathrm{L}) ; V_{j-1}$ 为第 $j-1$ 次采样体积 $(\mathrm{L}) ; A$ 为 沉积物一水界面面积 $\left(\mathrm{m}^{2}\right) ; t$ 为释放时间 $(\mathrm{d})$.

\section{3 分析测试方法}

按照 $0 \sim 1 、 1 \sim 2 、 2 \sim 4 、 4 \sim 6 、 6 \sim 8 、 8 \sim 10 、 10 \sim 15 、 15 \sim 20 \mathrm{~cm}$ 间隔对底泥柱状样品进行切割分层. 分层后的 底泥样品立即使用聚乙烯自封袋密封保存, 每一层底泥样品尽量扎紧袋口, 用手挤尽袋中的空气, 防止底泥 被氧化, 并置于冰箱冷藏保存. 分层后的湿泥样品 (注意每层泥样均需混合均匀) 一部分用坩埚于 $110^{\circ} \mathrm{C}$ 烘 箱烘干检测含水率, 另一部分置于自封袋冷冻干燥后用玛瑙研钵研磨成粉, 过 100 目 (0.150 mm) 分样篮, 装 人自封袋保存待测.

沉积物总氮 $(\mathrm{TN})$ 和总磷 $(\mathrm{TP})$ 含量按照《湖泊生态系统观测方法》规范 ${ }^{[24]}$ 采用碱性过硫酸钾消解一分 光光度法进行测定. 沉积物中弱结合态铵态氮 $\left(\mathrm{NH}_{4}^{+}-\mathrm{N}\right)$ 、硝态氮 $\left(\mathrm{NO}_{3}^{-}-\mathrm{N}\right)$ 的提取参考 Shannon 等 ${ }^{[25]}$ 的方法 进行; 沉积物磷形态根据 Rydin ${ }^{[26]}$ 的方法通过连续提取的方法进行磷分级, 分级出的磷形态包括: 可交换态 磷 (Ex-P)、钙磷 ( Ca-P)、铝磷 (Al-P)、铁磷 (Fe-P)、有机磷 ( OP)、残渣态磷 (Residual-P). 以上提取出的铵态 氮、硝态氮及磷形态样品分析参照《水和废水监测分析方法 (第四版) 》 ${ }^{[27]}$ 中的相应方法.

\section{4 数据分析}

白洋淀点位图由 Suffer 软件 (Golden software, Golden, Colorado, USA) 进行绘制; 数据图的绘制使用 Origin 9.0 (Origin Lab, Northampton, MA, USA) 软件完成; 各指标差异性分析使用单因素方差检验(ANOVA) 方法, 数据相关性分析使用 Pearson 相关性分析, 以上分析使用 SPSS 19.0 (IBM, New York, NY, USA) 软件完成.

\section{2 结果与讨论}

\section{1 沉积物 TN 和 TP 含量空间变化规律}

$\mathrm{TN}$ 含量在很大程度上可以反映出该地区沉积物的营养水平 ${ }^{[28]}$. 白洋淀基本特征是草型富营养化浅水 湖泊,氮是湖泊草型富营养化的限制因子 ${ }^{[12]}$. 由图 2 可知, 白洋淀沉积物 TN 含量在 $1230.8 \sim 9559.0 \mathrm{mg} / \mathrm{kg}$ 范围内, 平均含量为 $2379.5 \mathrm{mg} / \mathrm{kg}$, 与太湖 ( $\mathrm{TN}$ 含量为 $363.9 \sim 1534.8 \mathrm{mg} / \mathrm{kg})^{[29]}$ 、巢湖 ( $\mathrm{TN}$ 平均含量为 $1696.0 \mathrm{mg} / \mathrm{kg})^{[30]}$ 等典型的严重富营养化湖泊相比, 白洋淀沉积物 TN 含量较高, 说明淀内沉积物受到了严 重的氮素污染. 这与 Liang 等 ${ }^{[31]}$ 的研究结果相近, 其认为白洋淀沉积物氮污染尤为突出, 主要污染来源可能 是周围居民的生活污染以及水生植物的腐烂累积. 由于白洋淀水陆交错, 淀内环境复杂, 生长着大量的芦 苇、菹草等大型水生植物, 与太湖、巢湖等典型富营养化湖泊不同的是, 大型水生植物的长期腐烂累积可能 是导致沉积物中氮素富集的重要原因. 在采样过程中也发现, 白洋淀沉积物中富含大量尚未降解完全的植 物组织. 从沉积物 TN 含量空间分布情况看, 每个采样点的 TN 含量表现出很明显的差异性 $(P<0.01), \mathrm{BYD} 6$ 和 BYD7 的 TN 含量最高, 平均含量分别为 4437.9 和 $3535.2 \mathrm{mg} / \mathrm{kg}$, 为重度污染 ${ }^{[30]}$. TN 含量最低的样点是 BYD10, 平均含量为 $1194.7 \mathrm{mg} / \mathrm{kg}$; 其次是 BYD1 点, 平均含量为 $1391.88 \mathrm{mg} / \mathrm{kg}$, 污染程度相对较轻 ${ }^{[30]}$. 各点 位 TN 平均含量高低顺序依次为:BYD6 ( $4437.9 \mathrm{mg} / \mathrm{kg}$ )、BYD7(3535.2 mg/kg)、BYD11(2996.1 mg/kg)、BYD3 $(2766.1 \mathrm{mg} / \mathrm{kg}) 、$ BYD4 ( $2180.3 \mathrm{mg} / \mathrm{kg}) 、$ BYD9 $(2082.0 \mathrm{mg} / \mathrm{kg}) 、$ BYD2 ( $1980.5 \mathrm{mg} / \mathrm{kg}) 、$ BYD5 ( 1965.0 $\mathrm{mg} / \mathrm{kg}) 、 B Y D 8(1644.3 \mathrm{mg} / \mathrm{kg}) 、 B Y D 1(1391.9 \mathrm{mg} / \mathrm{kg}) 、 B Y D 10(1194.7 \mathrm{mg} / \mathrm{kg})$, 各区域氮污染程度差异显著 $(P<0.01)$.

不仅各采样点间 TN 含量差异性较大 $(P<0.01)$, 同一个采样点垂向上也呈现显著的差异, 表现为沉积 物 TN 含量总体上呈现自表层往下逐渐降低的趋势, 其中, BYD1、BYD5、BYD8 和 BYD10 点在 10 20 cm 处 沉积物中 TN 含量有上升趋势, 可能与历史上白洋淀曾有过干涸现象, 导致沉积状况发生改变有关 ${ }^{[32]}$. 白洋 
淀表层沉积物 TN 平均含量为 $2918.0 \mathrm{mg} / \mathrm{kg}$, 而 $15 \sim 20 \mathrm{~cm}$ 沉积物 TN 平均含量为 $2049.1 \mathrm{mg} / \mathrm{kg}$, 虽均处于重 污染程度 ${ }^{[30]}$, 但相比之下表层氮污染程度比深层更严重. 说明新近沉积造成的污染要显著高于历史沉积污 染, 白洋淀沉积物氮污染过去数十年来呈现不断加剧趋势. 此外, 从各点位垂向 TN 含量波动幅度看, 各点位 波动幅度大小依次是 BYD6 (6909.2 mg/ $\mathrm{kg}$ ) $>$ BYD11 $(2307.2 \mathrm{mg} / \mathrm{kg})>\operatorname{BYD} 7(1627.8 \mathrm{mg} / \mathrm{kg})>\operatorname{BYD} 9(1536.1$ $\mathrm{mg} / \mathrm{kg})>$ BYD8 $(1190.9 \mathrm{mg} / \mathrm{kg})>$ BYD3 $(1069.7 \mathrm{mg} / \mathrm{kg})>\operatorname{BYD} 5(866.1 \mathrm{mg} / \mathrm{kg})>\operatorname{BYD} 2(813.7 \mathrm{mg} / \mathrm{kg})>$ BYD10 ( 772.4 mg/ $/ \mathrm{kg})>\operatorname{BYD} 4(495.7 \mathrm{mg} / \mathrm{kg})>$ BYD1 $(330.6 \mathrm{mg} / \mathrm{kg}$ ), 说明各点位受到的历史污染累积状况存 在较大差异,不同区域氮污染来源及污染量可能存在较大差别.
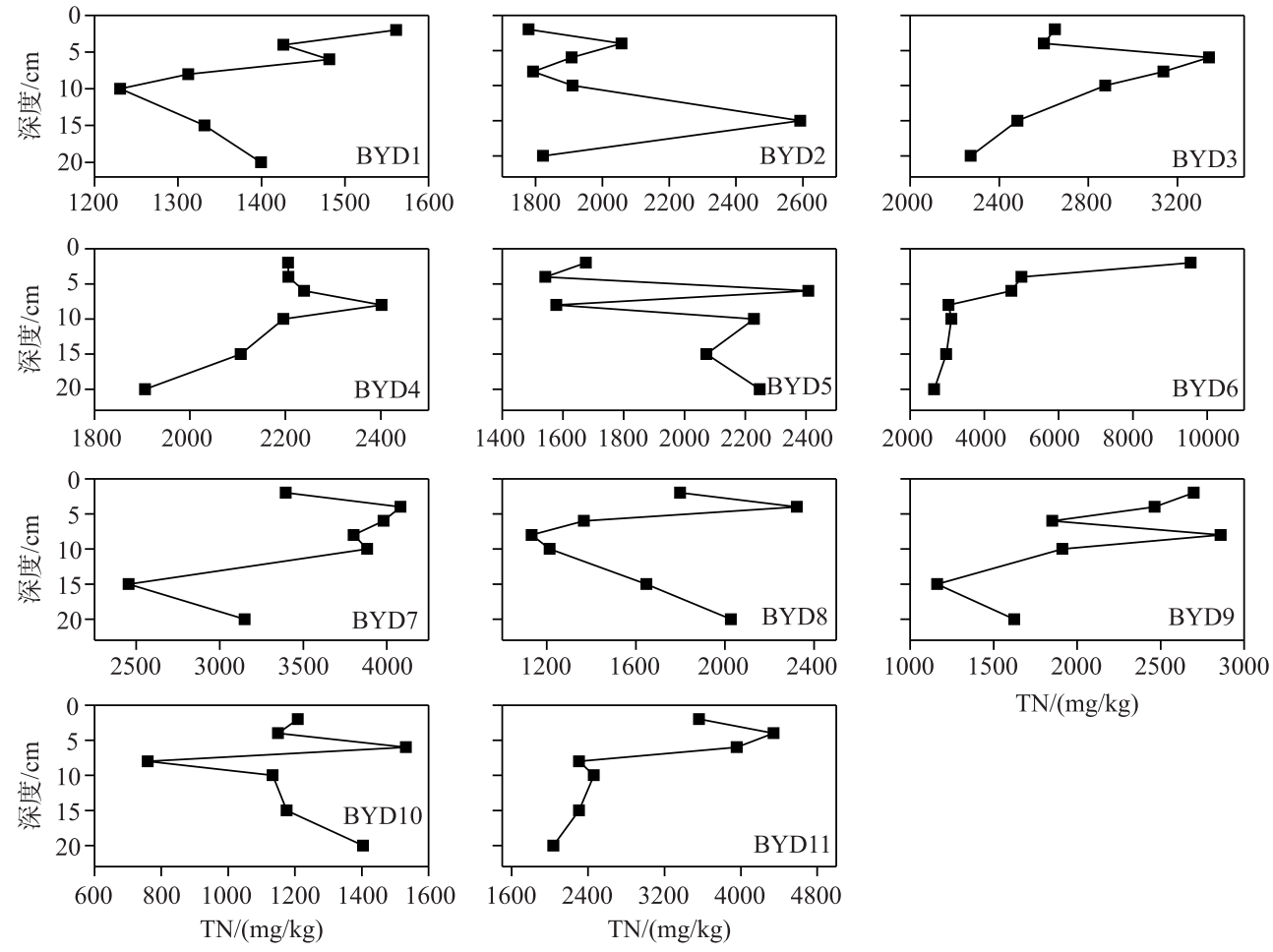

图 2 沉积物 TN 含量垂向分布

Fig.2 Vertical distributions of TN content in the sediments

白洋淀沉积物 TP 含量变化范围在 344.4 915.4 mg/ $\mathrm{kg}$ 之间, 平均含量为 $608.4 \mathrm{mg} / \mathrm{kg}$ (图 3), 与太湖平 均含量 $(600.0 \mathrm{mg} / \mathrm{kg})^{[31]}$ 相近, 低于巢湖平均含量 $(790.0 \mathrm{mg} / \mathrm{kg})^{[33]}$. 各采样点中, BYD7 的 TP 含量最高, 平 均含量为 $753.0 \mathrm{mg} / \mathrm{kg}$, 该点位于郭里口村附近, 同时处于府河人淀河口下游, 推测该点 TP 含量过高可能与 人为活动和人湖污染大量排放有关. 其次为 BYD 8 , 平均含量为 $730.1 \mathrm{mg} / \mathrm{kg}$, 该点位于泥李庄村下游, 并处 于府河人淀河口下游, 推测与 BYD7 点相似, 均是由人为活动和人湖污染长期冲击造成. TP 含量最小的点位 是 BYD11, 平均含量为 $451.1 \mathrm{mg} / \mathrm{kg}$. BYD11 点 TP 含量比较低的原因推测是因为该点位于白洋淀南边水域 较为开阔的范峪淀中央区域, 远离村落, 人为活动排放影响相对较小, 芦苇、香蒲生长茂盛, 水体自净能力较 强,使得该点位沉积物中磷污染累积较小. 从 TP 含量垂向分布看, 虽总体有自上而下沉积物 TP 含量减少的 趋势, 但在 BYD2、BYD4、BYD8、BYD9 和 BYD10 等点位中也出现了类似于 TN 含量分布的突变趋势, 可能与 水量变化导致的历史沉积改变和水生植物腐烂等因素有关.

以上分析表明,白洋淀沉积物氮、磷赋存含量较高, 受到了严重的氮、磷污染. 其中, BYD7 点附近区域 $\mathrm{TN} 、 \mathrm{TP}$ 含量相对较高, 根据已有研究结果 ${ }^{[32,34]}$, 这和该区域人类活动及大面积养殖有关, 生活污染及养殖过 程中饵料投喂汇人的大量氮、磷营养盐在沉积物中不断累积,使得该区域沉积物氮、磷污染突出. 

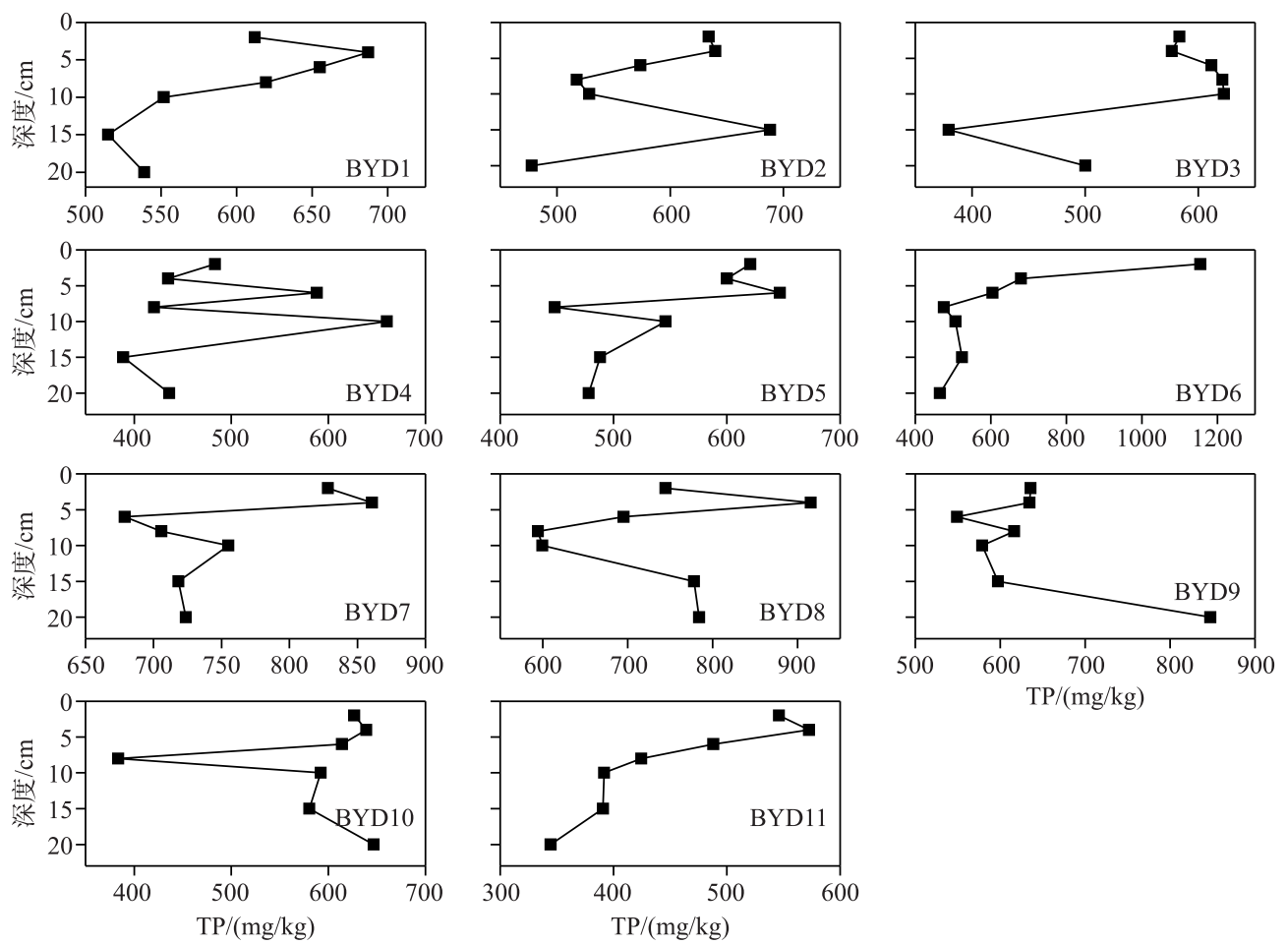

图 3 沉积物 TP 含量垂向分布

Fig.3 Vertical distributions of TP content in the sediments

\section{2 沉积物氮磷赋存形态特征}

对白洋淀沉积物中赋存的弱结合态铵态氮及硝态氮进行了分析, 结果发现 (图 4), 沉积物铵态氮含量在 $3.2 \sim 175.8 \mathrm{mg} / \mathrm{kg}$ 之间, 虽低于长江中下游富营养化突出的巢湖、太湖等湖泊典型重污染区域沉积物中铵态 氮含量 (116.4 705.4 mg/ $\mathrm{kg}^{[2,35]}$ ), 但依然存在着突出的铵态氮污染. 从垂向分布看, 随着沉积物深度的增 加, 铵态氮含量呈逐渐升高趋势. 其原因是随着深度增加, 沉积物中氧气逐渐减少, 呈现厌氧环境, 铵态氮更 容易形成并累积 ${ }^{[6-37]}$. 此外, 白洋淀沉积物中大量水生植物残体的降解加剧了厌氧环境, 采样过程中发现, 沉积物多呈现严重的黑臭状况, 由此进一步促进了铵态氮的形成. 各点位中, BYD7 点轱态氮含量相对较高, 平均含量为 $137.5 \mathrm{mg} / \mathrm{kg}$; BYD10 点铵态氮含量相对较低, 平均含量为 $7.8 \mathrm{mg} / \mathrm{kg}$, 沉积物中铵态氮含量与 TN 含量呈现显著的相关性 $(P<0.05)$. 沉积物中硝态氮含量总体在 $24.7 \sim 76.6 \mathrm{mg} / \mathrm{kg}$ 之间, 与长江中下游部分 湖泊沉积物中硝态氮含量相近 $(30.3 \sim 71.8 \mathrm{mg} / \mathrm{kg})^{[2]}$, 其中, BYD7 和 BYD11 点硝态氮含量较高, 这可能与 这 2 个点位较高的 TN 浓度密切相关. 从沉积物中弱结合态氮形态垂向分布看, 随着沉积物深度的增加, 硝 态氮的含量和比例逐渐降低而铵态氮的含量逐渐上升, 造成这一现象的主要原因可能是随着还原环境的加 剧, 沉积物中硝态氮向铵态氮不断转化 ${ }^{[36]}$.

从各点位磷形态总体分布状况看 (图 5), Ex-P 所占比例最低, 大约在 $0.2 \% \sim 7.5 \%$ 之间. 各采样点总体 上表层可交换磷所占比例比深层所占比例大, 随着深度的增加, Ex-P 所占比例逐渐减小. 在各个点位中, BYD7 点 Ex-P 所占比例较高, Ex-P 是最容易溶解释放的磷形态, 极易对间隙水中磷酸盐含量及沉积物一水 界面磷通量产生影响. Ca-P 所占比例最高, 这与其他研究人员对白洋淀的研究结果相近 ${ }^{[1,38]}$, 结合梁淑轩 等 ${ }^{[38]}$ 对白洋淀沉积物理化特征的分析数据可推测, Ca-P 含量高可能与白洋淀沉积物以黏土为主, 属于中性 偏碱性䥻化土壤有关. 各采样点中, BYD7 点 Ca-P 所占比例较低, 最低为 $38.3 \%$, 含量为 $309.2 \mathrm{mg} / \mathrm{kg}$; BYD10 点 Ca-P 所占比例较高, 最高达到 $76.1 \%$, 含量为 $404.8 \mathrm{mg} / \mathrm{kg}$. Ca-P 主要以水合磷酸钙 $\mathrm{Ca}_{5} \mathrm{OH}\left(\mathrm{PO}_{4}\right)_{3}$ 及少量 

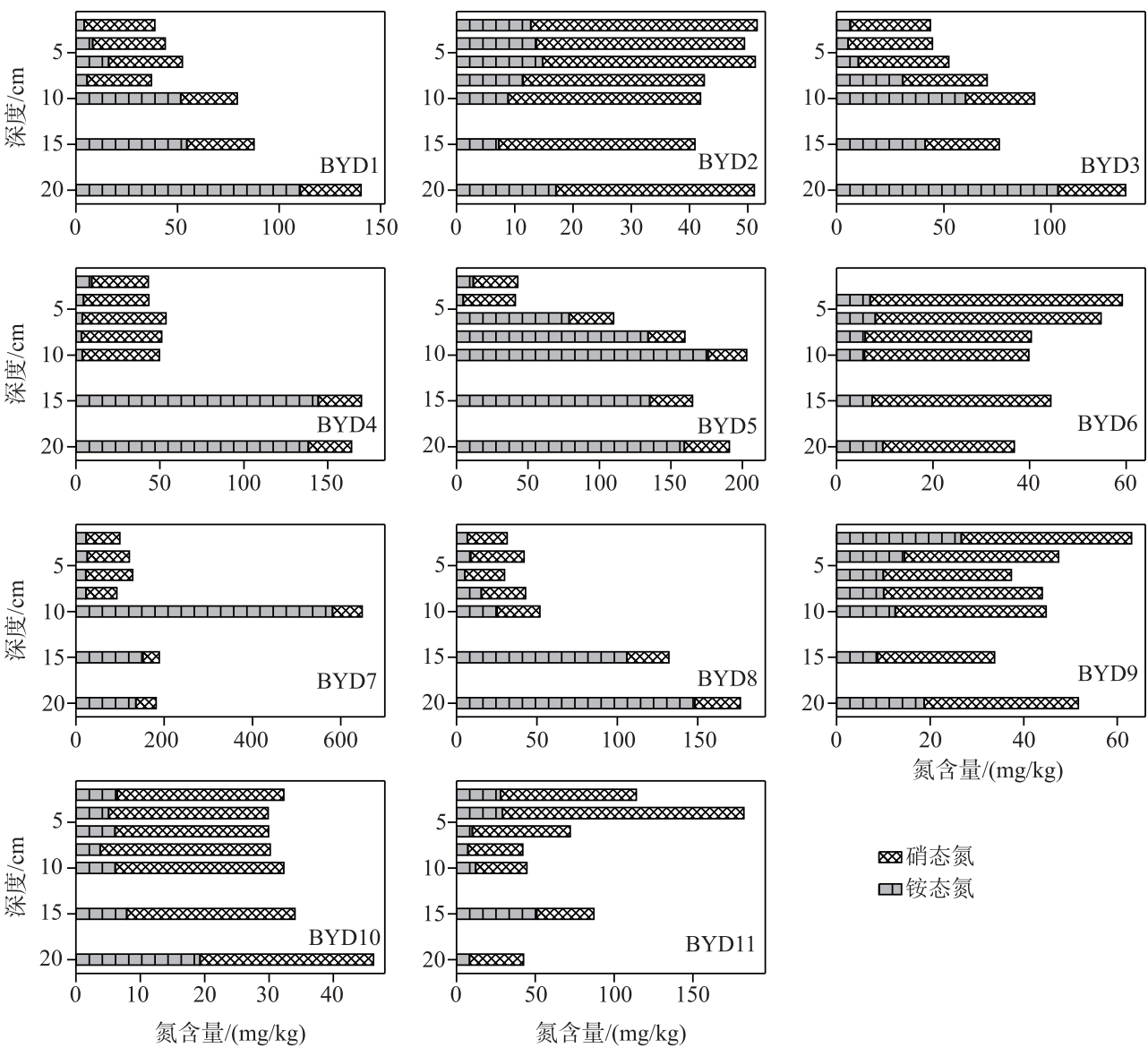

区硝态氮

口铵态氮

图 4 不同分层沉积物中弱结合态铵态氮及硝态氮含量

Fig.4 Contents of ammonium nitrogen and nitrate nitrogen in different stratified sediments

生物骨骼等形态存在 ${ }^{[39]}$, 被认为是比较稳定的磷形态 ${ }^{[40]}$, 已有研究表明 ${ }^{[41]}$, 沉积物中 Ca-P 较难被分解或转 化为磷酸盐, 因此对湖泊内源磷负荷相对较小. 沉积物中 Fe-P 含量仅次于 Ca-P, 所占比例范围在 3.98\% $18.0 \%$ 之间, BYD1 点表层沉积物中 Fe-P 所占比例最高, 达到 17.97\%. Fe-P 是影响沉积物一水界面磷交换的 重要磷形态, Ruban 等 ${ }^{[42]}$ 提出 $\mathrm{Fe}-\mathrm{P}$ 指示较高含量的污水输人磷; 袁和忠等 ${ }^{[43]}$ 提出表层沉积物中 Fe-P 的含 量可作为指示环境污染程度的指标之一; 根据 Jensen 等 ${ }^{[4]}$ 的研究, 沉积物中 Fe-P 与上覆水中磷酸盐浓度呈 显著相关, 在氧化还原环境变化下, 沉积物中磷与铁的同步释放是影响沉积物内源磷负荷的重要因 素 ${ }^{[5,45-46]}$. 因而, 白洋淀沉积物中高含量的 Fe-P 可能对沉积物一水界面磷交换及内源磷负荷产生重要影响. 从各点位磷形态分布看, BYD1 和 BYD7 点沉积物中 Fe-P 含量及其所占比例比其他采样点高, 这 2 个点位沉 积物中较高的 Fe-P 含量可能会加剧沉积物中磷的释放.

\section{3 沉积物间隙水氮磷剖面分布特征及其差异}

间隙水在沉积物一水界面氮、磷交换过程中起着重要的媒介作用,向上进人上覆水中影响水体中氮、磷 含量; 向下被沉积物中颗粒物吸附则成为氮、磷的“汇” ${ }^{[47]}$. 铵态氮浓度在经过沉积物一水界面后明显升高, 升高至一定浓度之后趋于平缓(图 6) (BYD2 和 BYD6 点间隙水数据缺失), 前述分析已经表明,随着沉积物 深度的增加, 沉积物中弱结合态铵态氮含量逐渐升高, 统计分析结果表明 (表 1), 间隙水中铵态氮浓度与沉积 物铵态氮含量及 TN 含量呈现极显著的正相关关系 $(P<0.01)$, 因而, 间隙水中铵态氮浓度总体呈现随着深度增 加而升高的趋势. BYD7 点间隙水铵态氮浓度相对于其他点位较高, 铵态氮浓度最高达到 $28.8 \mathrm{mg} / \mathrm{L}$, 这一浓度 

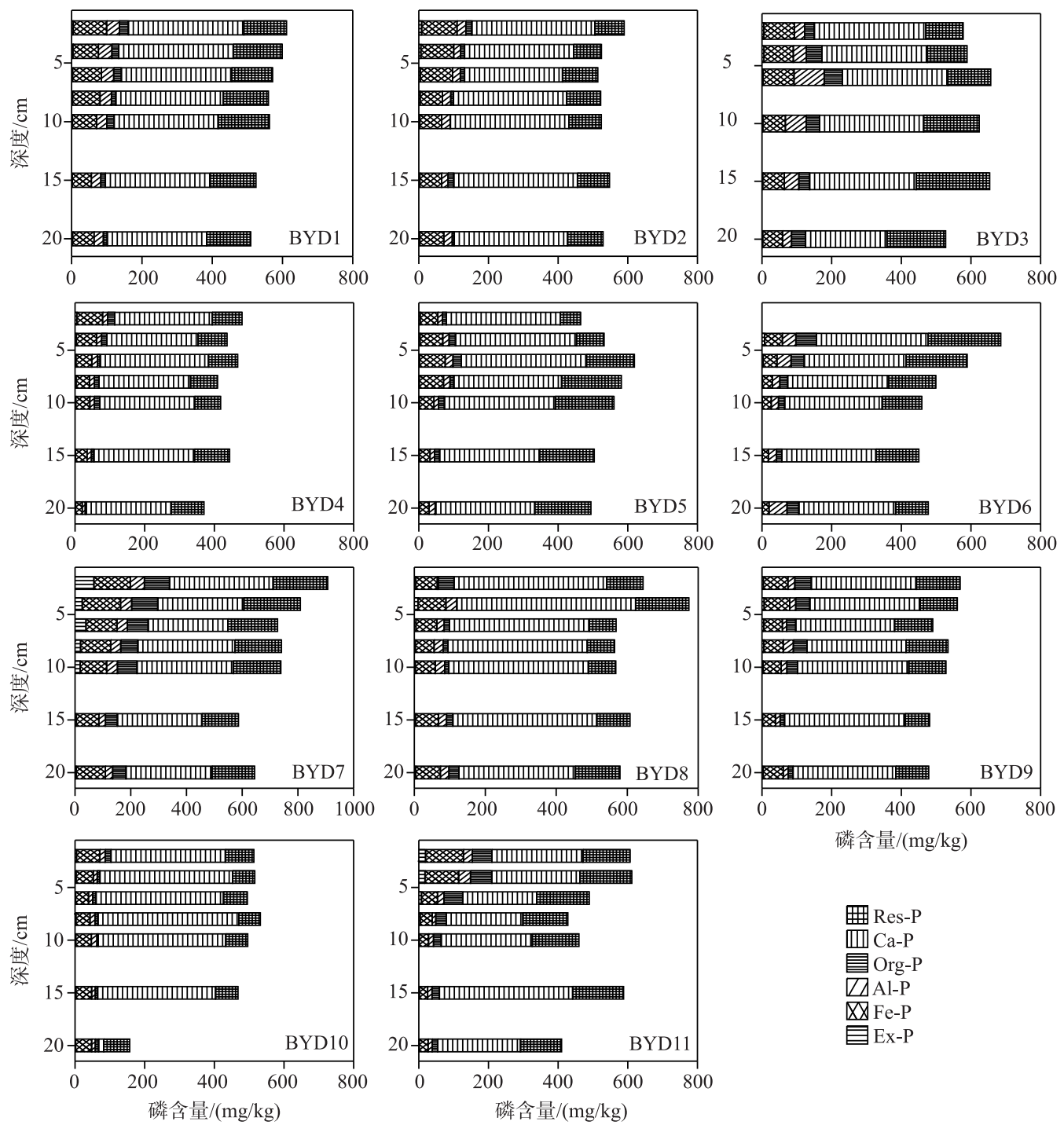

磷含量 $/(\mathrm{mg} / \mathrm{kg})$

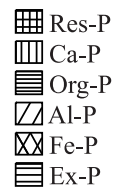

图 5 沉积物磷形态垂向分布状况

Fig.5 Vertical distributions of phosphorus fractions in the sediments

高于巢湖污染最为严重区域间隙水铵态氮浓度 $(\text { 约 } 10 \mathrm{mg} / \mathrm{L})^{[48]}$, 同时也高于太湖 $(<10 \mathrm{mg} / \mathrm{L})^{[48-49]}$ 、Erie 湖 $(<$ $4 \mathrm{mg} / \mathrm{L})^{[50]}$ 等典型富营养湖区间隙水中铵态氮浓度. 即使是各点位中间隙水铵态氮浓度较低的 BYD10 点, 其铵态氮浓度依然在 1.7 4.6 mg/L 之间, 仍高于多个富营养化湖区. 前述分析已表明, 白洋淀沉积物中大量 水生植物腐解造成的厌氧环境加剧了沉积物中弱结合态铵态氮的形成, 从而导致间隙水中铵态氮浓度与其 他富营养化湖泊相比处于较高水平. 由此说明, 白洋淀沉积物间隙水中铵态氮浓度较高, 存在着较大的扩 散、释放趋势,潜在内源氮负荷可能较高.

间隙水中磷酸盐浓度与铵态氮浓度呈现类似的趋势 (图 7), 均表现为自上覆水体至下层底泥不断上升 的趋势. BYD1 点间隙水磷酸盐浓度最高, 最大达到 $10.8 \mathrm{mg} / \mathrm{L}$; 其次是 BYD7 点, 间隙水磷酸盐浓度最高也 达到了 $3 \mathrm{mg} / \mathrm{L}$ 以上, 这一浓度高于巢湖污染较为严重的区域 (一般 $<2 \mathrm{mg} / \mathrm{L})^{[48]}$, 以及太湖 $(<2 \mathrm{mg} / \mathrm{L})^{[49]}$ 、 琵琶湖 $(3.4 \mathrm{mg} / \mathrm{L})^{[51]}$ 等典型富营养化湖泊, 存在较高释放风险. 这 2 个点位中较高的磷酸盐浓度可能与沉 积物中较高含量的 Fe-P 有关, 由于所采集的沉积物多呈现明显的黑臭状况, 沉积物中大量水生植物残体的 
腐解使得其氧化还原条件较差, 厌氧条件下, $\mathrm{Fe}^{3+}$ 容易被还原为 $\mathrm{Fe}^{2+}$, 由此导致沉积物中 $\mathrm{Fe}-\mathrm{P}$ 在还原条件下 的溶解和释放,使得间隙水中磷酸盐浓度升高 ${ }^{[5,45,52]}$. BYD11 点间隙水中磷酸盐浓度最低, 范围在 $0.2 \sim$ $0.7 \mathrm{mg} / \mathrm{L}$ 之间,其余点位间隙水中磷酸盐浓度一般在 $0.2 \sim 3 \mathrm{mg} / \mathrm{L}$ 之间, 依然与太湖、巢湖等典型富营养化 湖泊中类似 ${ }^{[49]}$. 以上分析表明, 白洋淀沉积物间隙水中铵态氮与磷酸盐浓度均较高, 存在较高的释放风险.

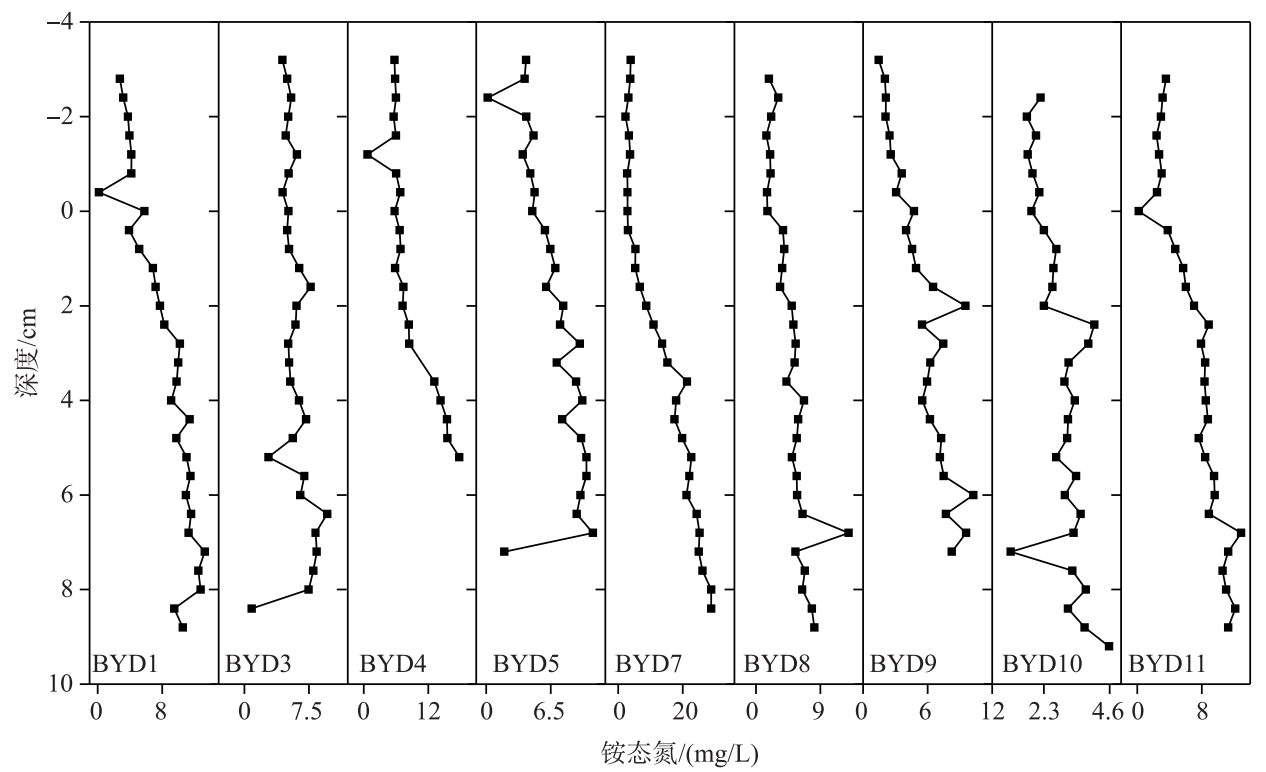

图 6 各采样点间隙水铵态氮浓度

Fig.6 Concentrations of ammonium nitrogen in the interstitial water at each sampling site

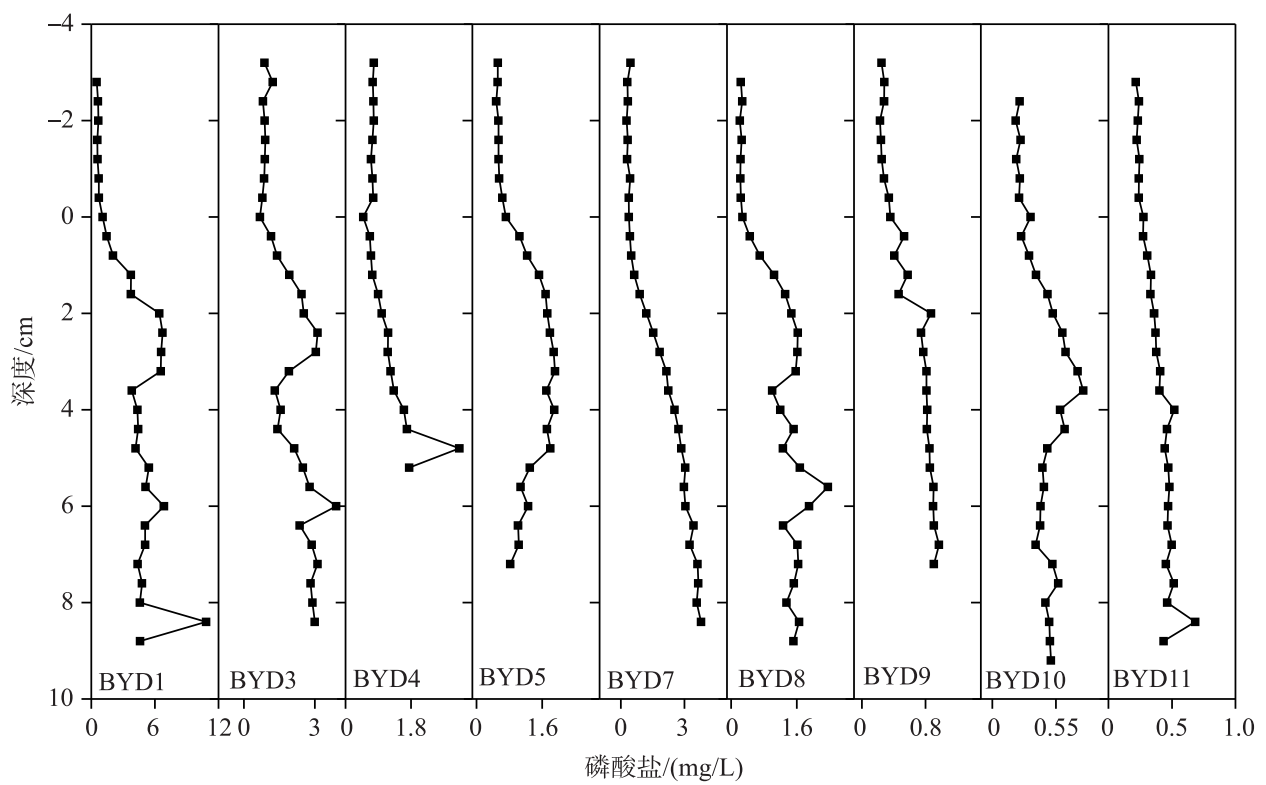

图 7 各采样点间隙水磷酸盐浓度

Fig.7 Concentrations of phosphorus in interstitial water at each sampling site 


\section{4 沉积物一水界面氮、磷交换特征分析}

根据式 (1) 和式 (2) 计算了沉积物铵态氮和磷酸盐的扩散和释放通量, 结果见图 8. 在进行沉积物静态 培养实验的过程中发现, 各沉积物柱样氮、磷释放速率基本在实验开始后的 $48 \mathrm{~h}$ 左右趋于平衡, 这与范成新 等 ${ }^{[53]}$ 在太湖的研究结果相近. 随着释放时间的增加, 沉积物中铵态氮及磷酸盐不断释放, 上覆水中铵态氮 及磷酸盐浓度不断增大, 当上覆水与间隙水之间达到扩散一释放平衡之后, 沉积物一水界面扩散及释放通量 也逐渐趋于平衡. 从白洋淀沉积物一水界面铵态氮和磷酸盐交换通量值看, 铵态氮释放通量变化范围为 $18.28 \sim 193.99 \mathrm{mg} /\left(\mathrm{m}^{2} \cdot \mathrm{d}\right)$, 均值为 $106.37 \mathrm{mg} /\left(\mathrm{m}^{2} \cdot \mathrm{d}\right)$; 扩散通量变化范围为 $1.61 \sim 33.30 \mathrm{mg} /\left(\mathrm{m}^{2} \cdot \mathrm{d}\right)$, 均值 为 $12.42 \mathrm{mg} /\left(\mathrm{m}^{2} \cdot \mathrm{d}\right)$. 各点位间铵态氮释放通量和扩散通量差异显著 $(P<0.01)$. 铵态氮释放通量与巢湖 污染较严重区域相近 $\left(14.27 \sim 128.24 \mathrm{mg} /\left(\mathrm{m}^{2} \cdot \mathrm{d}\right)\right)^{[54]}$, 接近或高于太湖月亮湾 $\left(30.6 \mathrm{mg} /\left(\mathrm{m}^{2} \cdot \mathrm{d}\right)\right)^{[55]}$ 、太湖

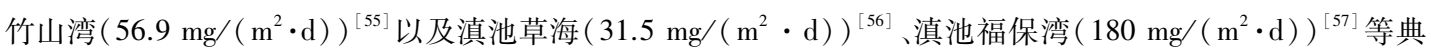
型重度富营养化湖区. 各区域铵态氮释放通量与扩散通量呈现相似的变化特征(图 8), 自 BYD1 点至 BYD7 点, 铵态氮释放及扩散通量总体呈现上升趋势, BYD7 点铵态氮释放及扩散通量在各点位中均最高, 根据前 述沉积物氮赋存形态分析结果, 该点位沉积物中铵态氮含量较高, 相关性分析结果显示 (表 1), 沉积物一水 界面铵态氮释放及扩散通量与沉积物及间隙水铵态氮含量存在显著正相关性 (表 $1, P<0.05$ ). 磷酸盐释放通 量变化范围为 $2.63 \sim 48.35 \mathrm{mg} /\left(\mathrm{m}^{2} \cdot \mathrm{d}\right)$, 均值为 $15.06 \mathrm{mg} /\left(\mathrm{m}^{2} \cdot \mathrm{d}\right)$; 磷酸盐扩散通量变化范围为 $0.15 \sim 13.01 \mathrm{mg} /$ $\left(\mathrm{m}^{2} \cdot \mathrm{d}\right)$, 均值为 $2.33 \mathrm{mg} /\left(\mathrm{m}^{2} \cdot \mathrm{d}\right)$. 各点位间磷酸盐释放通量和扩散通量差异显著 $(P<0.01)$. 磷酸盐释放通量 显著高于巢湖污染较为严重区域 $\left(0.07 \sim 13.00 \mathrm{mg} /\left(\mathrm{m}^{2} \cdot \mathrm{d}\right)\right)^{[54]}$ 、太湖五里湖水域 $\left(<6.00 \mathrm{mg} /\left(\mathrm{m}^{2} \cdot \mathrm{d}\right)\right)^{\left[{ }^{[5]}\right]}$ 以及 其他区域 ${ }^{[59]}$; 磷酸盐扩散通量显著高于太湖沉积物磷扩散速率 $\left(<1.00 \mathrm{mg} /\left(\mathrm{m}^{2} \cdot \mathrm{d}\right)\right)^{[59]}$. 总体上, 各点位磷酸 盐释放与扩散通量呈现一致的变化趋势 ( 表 $1, P<0.05$ ), 并与间隙水中磷酸盐浓度呈现极显著正相关性 (表 1 , $P<0.01)$. 沉积物一水界面磷酸盐扩散及释放通量呈现北部湖区往南逐渐降低趋势, 且 BYD1 和 BYD3 点呈现 出较高的磷酸盐通量. 这可能与北部人湖河流 (白沟引河) 长期汇人的污染有关. 由于磷极易吸附在人湖河流 所携带的大量颗粒物上 ${ }^{[46]}$, 其在河口区域的沉降导致河口区域沉积物磷污染及内源磷负荷突出.
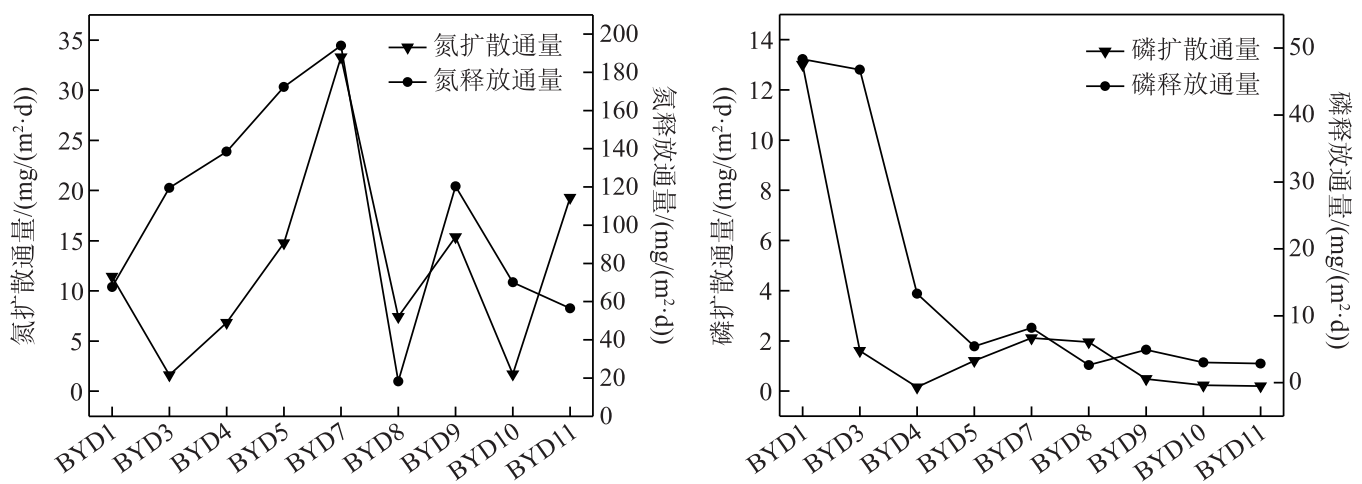

图 8 沉积物中氮和磷的释放和扩散通量

Fig. 8 Nitrogen and phosphorus release and diffusion fluxes from the sediments

综上所述, 白洋淀沉积物具有较高的氮、磷赋存量及较大的内源氮、磷负荷. 其中, 氮的赋存量和内源负 荷比磷更为突出. 氮、磷内源负荷高的原因一方面是沉积物中氮、磷本身赋存量较大; 另一方面, 白洋淀沉积 物中弱结合态氮、Ex-P 及 Fe-P 含量较高, 调研过程中发现白洋淀沉积物多呈现严重黑臭状态, 淀内大量水 生植物残体的长期持续累积和降解导致沉积物处于严重戻氧状态. 在此环境下, 沉积物中赋存的高含量的 弱结合态氮、Ex-P 及 Fe-P 极易溶解至间隙水中并释放至上覆水体 ${ }^{[5,36,45]}$. 整个淀区北部沉积物氮、磷赋存量 及内源负荷量显著高于南部淀区, 以 BYD1 点及其附近区域为代表的典型重污染河口区域 (白沟引河河口) 和 BYD7 点及其附近区域为代表的典型人类密集活动和人湖污染负荷冲击区域 ( 郭里口村、泥李庄村和大 张庄村附近区域, 处于府河人淀河口下游) 是淀区沉积物氮、磷内源污染的集中区域,这两个区域内沉积物 严重黑臭且内源氮、磷负荷量大, 对水质形成较大威胁, 应成为淀区沉积物内源氮、磷负荷整治的关键区域. 


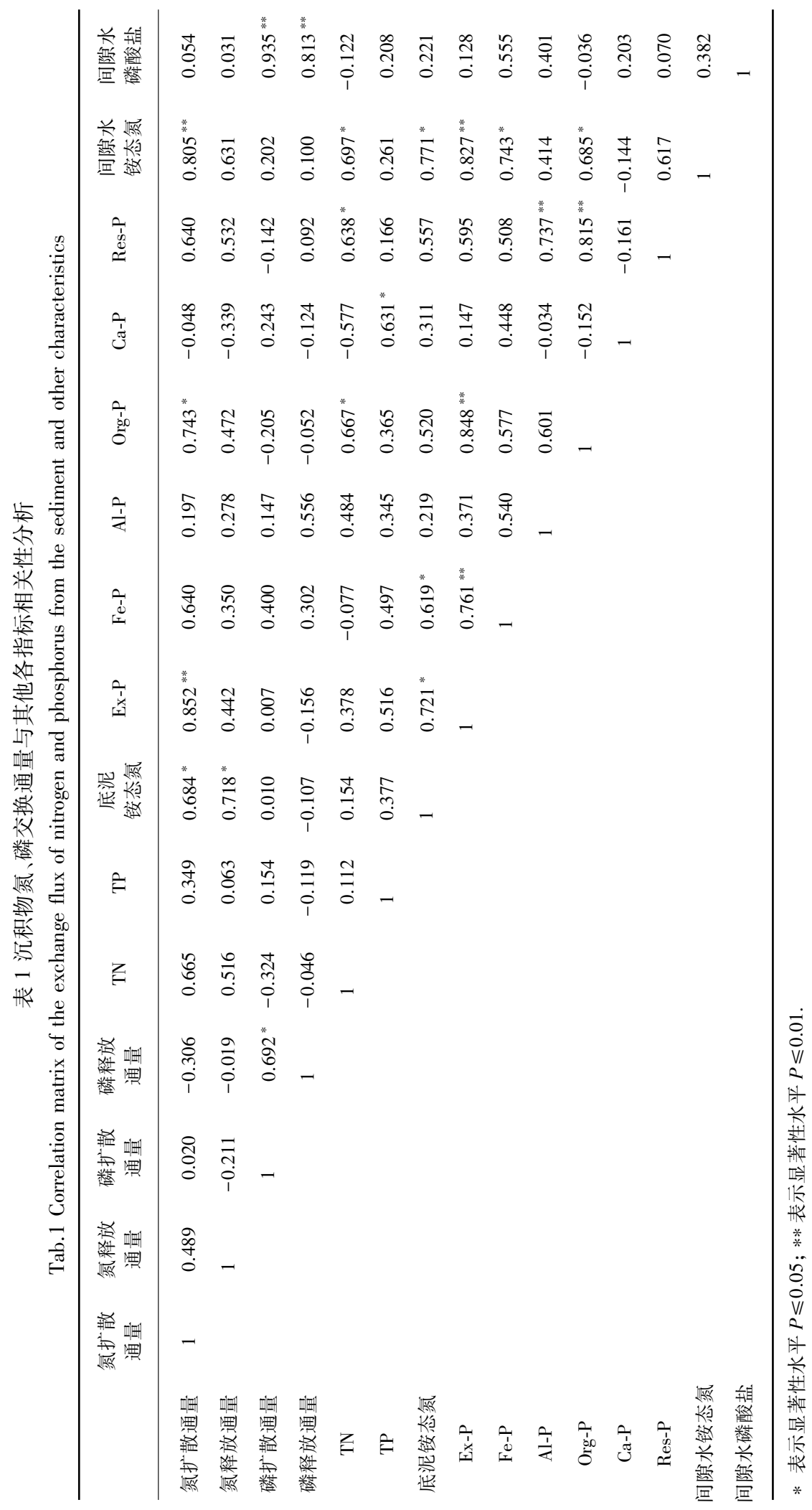




\section{3 结论}

1) 白洋淀沉积物 TN、TP 含量分别为 1230.8 9559.0 和 $344.4 \sim 915.4 \mathrm{mg} / \mathrm{kg}$, 平均含量分别达到 2379.5 和 $608.4 \mathrm{mg} / \mathrm{kg}$, 存在严重的氮、磷污染, 且沉积物中氮的累积比磷更加突出. 淀区北部沉积物氮、磷含量总 体高于南部, 其中, 郭里口村、泥李庄村和大张庄村附近区域内沉积物氮、磷赋存量明显高于淀区其他区域, 说明人类活动是白洋淀沉积物氮、磷污染的主要来源.

2) 白洋淀沉积物内源氮、磷负荷较高, 沉积物一水界面铵态氮平均释放和扩散通量分别为 106.37 和 $12.42 \mathrm{mg} /\left(\mathrm{m}^{2} \cdot \mathrm{d}\right)$; 磷酸盐平均释放和扩散通量分别为 15.06 和 $2.33 \mathrm{mg} /\left(\mathrm{m}^{2} \cdot \mathrm{d}\right)$. 沉积物中高含量的弱结 合态氮、Ex-P、Fe-P 以及沉积物黑臭所形成的还原环境可能是导致内源氮、磷负荷高的直接原因. 界面氮、磷 交换通量接近或高于我国多个典型重度富营养湖区, 说明内源负荷对白洋淀水体富营养化贡献较大, 已成 为白洋淀水生态环境整治过程中迫切需要解决的问题.

3) 北部河口区域和中部人类密集活动与人淀污染冲击叠加区域是白洋淀沉积物氮、磷污染主要区域, 也是内源氮、磷负荷较高的区域, 这两个区域内沉积物严重黑臭且内源氮、磷负荷量大, 对水质形成较大威 胁,应成为淀区沉积物内源氮、磷负荷整治的关键区域.

\section{4 参考文献}

[ 1 ] Conley DJ, Likens GE. Ecology. Controlling eutrophication: nitrogen and phosphorus. Science, $2009,323(5917)$ : 1014.

[ 2 ] Wang SR ed. Sediment-water interface process of lakes. Beijing: Science Press, 2014. [王圣瑞. 湖泊沉积物一水界面过 程. 北京: 科学出版社, 2014.]

[ 3 ] Vicente ID, Serrano L, Amores V et al. Sediment phosphate fractionation and interstitial water phosphate concentration in two coastal lagoons (Albuferas de Adra, SE Spain). Hydrobiologia, 2003, 492 (1-3) : 95-105.

[ 4 ] Søndergaard M, Jensen JP, Jeppesen E. Role of sediment and internal loading of phosphorus in shallow lakes. Hydrobiologia, 2003, 506-509(1-3) : 135-145.

[ 5 ] Petticrew EL, Arocena JM. Evaluation of iron-phosphate as a source of internal lake phosphorus loadings. Science of the Total Environment, 2001, 266(1-3) : 87.

[ 6 ] Kleeberg A, Kohl JG. Assessment of the long-term effectiveness of sediment dredging to reduce benthic phosphorus release in shallow Lake Müggelsee (Germany). Hydrobiologia, 1999, 394(3) : 153-161.

[ 7 ] Nürnberg GK, Tarvainen M, Ventelä AM et al. Internal phosphorus load estimation during biomanipulation in a large polymictic and mesotrophic lake. Inland Waters, 2015, 2(3) : 147-162.

[ 8 ] Jeppesen E, Meerhoff M, Jacobsen BA et al. Restoration of shallow lakes by nutrient control and biomanipulation-The successful strategy varies with lake size and climate. Netherlands: Springer, 2007: 269-285.

[ 9 ] Gao NN, Li XW, Zhuge HJ. Relationship between raised field structure and europhication extent change of water in Baiyangdian lake. Wetland Science, 2013, 11(2) : 259-265. [高楠楠, 李晓文, 诸葛海锦. 白洋淀台田结构与水体富营养 化程度变化的关系研究. 湿地科学, 2013, 11(2) : 259-265.]

[10] Zhang SZ, li GB. The wet land ecological survice function and value estimation of the Baiyangdian lake wetland. South-toNorth Water Transfers and Water Science \& Technology, 2005, 3(4) : 22-25. [张素珍, 李贵宝. 白洋淀湿地生态服务 功能及价值估算. 南水北调与水利科技, 2005, 3(4): 22-25.]

[11] Diao SR. Comprehensive evaluation of eutrophication in Baiyangdian. Environmental Science, 1995，( s1): 28-29. [ フ淑 荣. 白洋淀富营养化水平综合评价. 环境科学, 1995, (s1) : 28-29.]

[12] Wang J, Pei YS, Yang ZF. Effects of nutrients on the plant type eutrophication of the Baiyangdian Lake. China Environmental Science, 2010, 30(s1) : 7-13. [王珺, 裴元生, 杨志峰. 营养盐对白洋淀草型富营养化的驱动与限制. 中国环 境科学, $2010,30(\mathrm{~s} 1): 7-13$.

[13] Gao QS, Jiao LX, Yang L et al. Occurrence and ecological risk assessment of typical persistent organic pollutants in Baiyangdian Lake. Environmental Science, 2018, 39(4): 1-16. [高秋生, 焦立新, 杨柳等. 白洋淀典型持久性有机污染 物污染特征与风险评估. 环境科学, 2018, 39(4): 1-16.]

[14] Wang YQ, Xue PY, Geng LP et al. Distribution characterics of nittrogen and phosphorus in sediments-submerged macro- 
phytes-water system of Baiyangdian Lake. Journal of Soiland Water Conservation, 2017, 31(3) : 304-309. [王亚琼, 薛 培英, 耿丽平等. 白洋淀沉积物-沉水植物-水系统氮、磷分布特征. 水土保持学报, 2017, 31(3) : 304-309.]

[15] Zhang T, Liu JL, Wang XM. Causal analysis of the spatial temporal variation of the water quality of Baiyangdian Lake. Acta Scientiae Circumstantiae, 2010,30(2) : 261-267. [张婷, 刘静玲, 王雪梅. 白洋淀水质时空变化及影响因子评价 与分析. 环境科学学报, $2010, \mathbf{3 0}(2): 261-267$.

[16] Wang TT, Cui BS, Liu PP et al. Effect of floating plants on distributions of emergent and submerged plants in Baiyangdian Lake. Wetland Science, 2013, 11(2) : 266-270. [王婷婷, 崔保山, 刘佩佩等. 白洋淀漂浮植物对挺水植物和沉水植 物分布的影响. 湿地科学, 2013, 11(2): 266-270.]

[17] Zhang ZR. Contamination characteristics and release mechanism in sediment of Baiyangdian Lake[Dissertation]. Baoding: Hebei University, 2013. [张振冉. 白洋淀沉积物污染特征及扰动释放研究 [学位论文]. 保定: 河北大学, 2013.]

[18] Wen CH. Determination on heavy metals and distributing on Baiyangdian Lake[Dissertation]. Baoding: Hebei University, 2009. [温春辉.白洋淀地区重金属的检测及分布 [学位论文]. 保定:河北大学, 2009.]

[19] Hu GC, Guo JY, Luo XJ et al. Distribution, sources, and risk assessment of polycyclic aromatic hydrocarbons (PAHs) in surface sediments from Baiyangdian Lake. Research of Environmental Science, 2009, 22(3): 321-326. [胡国成, 郭建 阳, 罗孝俊等. 白洋淀表层沉积物中多环芳烃的含量、分布、来源及生态风险评价. 环境科学研究, 2009, 22(3): 321-326.]

[20] Laskov C, Herzog C, Lewandowski J et al. Miniaturized photometrical methods for the rapid analysis of phosphate, ammonium, ferrous iron, and sulfate in pore water of freshwater sediments. Limnology and Oceanography Methods, 2007, 5 (1) : 63-71.

[21] Ullman WJ, Aller RC. Diffusion coefficients in nearshore marine sediments. Limnology and Oceanography, 1982, 27( 3) : $552-556$

[22] Krom MD, Berner RA. The diffusion coefficients of sulfate, ammonium, and phosphate ions in anoxic marine sediments. Limnology and Oceanography, 1980, 25(2) : 327-337.

[23] Fan CX, Zhang L, Yang LY et al. Simulation of internal loadings of nitroen and phosorous in a lake. Oceanologia et Limnologia Sinica, 2002, 33(4) : 370-378. [范成新, 张路, 杨龙元等. 湖泊沉积物氮磷内源负荷模拟. 海洋与湖沼, $2002,33(4)$ : 370-378.

[24] Chen WM. Observation method of lake ecosystem. Beijing: China Environmental Science Press, 2005. [ 陈伟民. 湖泊生态 系统观测方法. 北京: 中国环境科学出版社, 2005.]

[25] Shannon KE, Saleh-Lakha S, Burton DL et al. Effect of nitrate and glucose addition on denitrification and nitric oxide reductase (cnorB) gene abundance and mRNA levels in Pseudomonas mandelii inoculated into anoxic soil. Antonie Van Leeuwenhoek, 2011, 100(2) : 183-195.

[26] Rydin E. Potentially mobile phosphorus in Lake Erken sediment. Water Research, 2000, 34(7) : 2037-2042.

[27] Ministry of Environmental Protection of the People's Republic of China, Editorial Board of Water and Wastewater Monitoring and Analysis Methods eds. Water and Wastewater Monitoring and Analysis Methods: 4th edition. Beijing: China Environmental Science Press, 2002. [ 国家环境保护总局《水和废水监测分析方法》编委会. 水和废水监测分析方法: 第 4 版. 北京: 中国环境科学出版社, 2002.]

[28] Wang SR, Jiao LX, Jin XC et al. Distribution of total, exchangeable and fixed nitrogen in the sediments from shallow lakes in the middle and lower reaches of the Yangtze River. Acta Science Circumstantiae, 2008, 28(1): 37-43. [王圣瑞, 焦立 新, 金相灿等. 长江中下游浅水湖泊沉积物总氮、可交换态氮与固定态铵的赋存特征. 环境科学学报, 2008, 28 (1) : 37-43.

[29] Fan CX ed. Sediment-water interface of lakes, processes and effects. Beijing: Science Press, 2013. [范成新. 湖泊沉积 物界面过程与效应. 北京: 科学出版社, 2013.]

[30] Zan F, Huo S, Xi B et al. Phosphorus distribution in the sediments of a shallow eutrophic lake, Lake Chaohu, China. Environmental Earth Sciences, 2011, 62(8): 1643-1653.

[31] Liang SX, Yan X, Qin Z. Spatial distribution of nitrogen salts in interstitial water and overlying water in Baiyangdian Lake. Journal of Environment \& Health, 2011, 28(1) : 47-49.

[32] Liang SX, Qin Z, Zhang ZR et al. Discussion on the policies of environmengtal protetion on the basis of investigation of the internal polution loadings in Baiyangdian Lake. Chinese Journal of Environmental Management, 2014, 6(1): 10-14. [梁 
淑轩, 秦哲, 张振申等. 从白洋淀内源污染调查探析其环境保护对策. 中国环境管理, 2014, 6(1): 10-14.]

[33] Wen SF, Shan BQ, Zhang H. Spatial distribution character of phosphorus fractions in surface sediment from Chaohu Lake. Environmental Science, 2012, 33(7) : 2322.

[34] Jiang YS, Chen H, Ma ZM et al. Field study on effect of harvesting submerged plant during growing season for ecological management of eutrophicated water. Chinese Journal of Environmental Engineering, 2013, 7(4) : 1351-1358. [姜义帅, 陈影, 马作敏等. 利用沉水植物生长期收割进行富营养化水体生态管理的实地研究. 环境工程学报, 2013, 7(4): 1351-1358. ]

[35] Liu C, Shao SG, Fan CX et al. Destribution and release risk of nitrogen in the sediment of heavily polluted confluence bay of Chaohu lake. Research of Environmental Science, 2014, 27(11): 1258-1264. [刘成, 邵世光, 范成新等. 巢湖重污 染汇流湾区沉积物营养盐分布与释放风险. 环境科学研究, 2014, 27(11) : 1258-1264.]

[36] Brandes JA, Devol AH. Isotopic fractionation of oxygen and nitrogen in coastal marine sediments. Geochimica et Cosmochimica Acta, 1997, 61(9): 1793-1801.

[37] Ditoro D M, Paquin P R, Subburamu K et al. Sediment oxygen demand model: Methane and ammonia oxidation. Journal of Environmental Engineering, 1992, 116(5) : 945-986.

[38] Liang SX, Zhang ZR, Qin Z et al. On the physico-chemical characteristic features and the nutrient distribution in the sediments of Lake Baiyangdian. Journal of Safety and Environment, 2016, 16(1) : 294-298. [梁淑轩, 张振再, 秦哲等. 白 洋淀沉积物理化特性及营养盐分布特征. 安全与环境学报, 2016, 16(1) : 294-298.]

[39] Xia XH, Dong YMX, Zhou JM et al. Geochemistry and influence to environment of phosphorus in modern sediment in Dianchi Lake. Acta Sedimentologica Sinica, 2002, 20(3) : 416-420. [夏学惠, 东野脉兴, 周建民等. 滇池现代沉积物中 磷的地球化学及其对环境影响. 沉积学报, 2002, 20(3): 416-420.]

[40] Gonsiorczyk T, Casper P, Koschel R. Phosphorus-binding forms in the sediment of an oligotrophic and an eutrophic hardwater lake of the Baltic Lake District (Germany). Water Science \& Technology, 1998, 37(3) : 51-58.

[41] Hou L, Jianjian LU, Min L. Species and bioavailability of phosphorus in surface sediments from the shoals in the Yangtze Estuary. Acta Scientiae Circumstantiae, 2006, 26(3) : 488-494.

[42] Ruban V, López-Sánchez JF, Pardo P et al. Harmonized protocol and certified reference material for the determination of extractable contents of phosphorus in freshwater sediments-a synthesis of recent works. Fresenius Journal of Analytical Chemistry, 2001, 370(2/3): 224-228.

[43] Yuan HZ, Shen J, Liu EF et al. Space distribution characteristics and diversity analysis of phosphorus from overlying water and surface sediments in Taihu Lake. Environmental Science, 2010, 31(4) : 954-960. [袁和忠, 沈吉, 刘恩峰等. 太湖 水体及表层沉积物磷空间分布特征及差异性分析. 环境科学, 2010, 31(4) : 954-960.]

[44] Jensen HS, Bo T. Iron-bound phosphorus in marine sediments as measured by bicarbonate-dithionite extraction. Hydrobiologia, 1993, 253(1/2/3) : 47-59.

[45] Hupfer M, Lewandowski J. Oxygen controls the phosphorus release from lake sediments-a Long-Lasting Paradigm in Limnology. International Review of Hydrobiology, 2008, 93(4/5) : 415-432.

[46] Liu C, Shao S, Shen Q et al. Effects of riverine suspended particulate matter on the post-dredging increase in internal phosphorus loading across the sediment-water interface. Environmental Pollution, 2016, 211: 165.

[47] Zhang RY, Wang LY, Wu FC et al. Distribution patterns of phosphorus forms in sediments interstitial water of Lake Taihu and the effects of sediment-water phosphorus release in spring. Chinese Journal of Ecology, 2012, 31(4) : 902-907. [张 润宇, 王立英, 吴丰昌等. 太湖春季沉积物间隙水中磷的分布特征及界面释放的影响. 生态学杂志, 2012,31 (4) : 902-907.]

[48] Liu C, Shao S, Shen Q et al. Use of multi-objective dredging for remediation of contaminated sediments: A case study of a typical heavily polluted confluence area in China. Environmental Science \& Pollution Research International, 2015, 22 (22) : 17839-17849.

[49] Fan CX, Zhang L eds. Lake Taihu:Principles of sediment pollution and remediation. Beijing: Science Press, 2016. [范成 新, 张路. 太湖——沉积物污染与修复原理. 科学: 科学出版社, 2016.]

[50] Adams DD, Matisoff G, Snodgrass WJ. Flux of reduced chemical constituents $\left(\mathrm{Fe}^{2+}, \mathrm{Mn}^{2+}, \mathrm{NH}_{4}^{+}\right.$and $\left.\mathrm{CH}_{4}\right)$ and sediment oxygen demand in Lake Erie. Netherlands: Springer, 1982: 17-37.

[51] Murphy T, Lawson A, Kumagai M et al. Release of phosphorus from sediments in Lake Biwa. Limnology, 2001, 2(2): 
119-128.

[52] Kim LH, Choi E, Stenstrom MK. Sediment characteristics, phosphorus types and phosphorus release rates between river and lake sediments. Chemosphere, 2003, 50(1): 53.

[53] Fan CX, Zhang L, Bao XM et al. Migration mechanism of biogenic elements and their quantification on the sediment-water interface of Lake Taihu: II . chemical thermodynamic mechanism of phosphorus release and its source-sink transition. $J$ Lake Sci, 2006, 18(3) : 207-217. DOI: 10.18307/2006.0303. [范成新, 张路, 包先明等. 太湖沉积物-水界面生源 要素迁移机制及定量化一2. 磷释放的热力学机制及源-汇转换. 湖泊科学, 2006, 18(3): 207-217.]

[54] Liu C, Shao SG, Fan CX et al. Destribution and release risk of heavy metais in the sediment of heavily polluted confluence bay of Chaohu lake. China Environmental Science, 2014, 34(4)：1031-1037. [刘成, 邵世光, 范成新等. 巢湖重污染 汇流湾区沉积物重金属污染特征及风险评价. 中国环境科学, 2014, 34(4) : 1031-1037.]

[55] Fan CX, Zhang L, Qin BQ et al. Migration mechanism of biogenic elements and their quantification on the sediment-water interface of Lake Taihu: I spatial variation of the ammonium rlease rates and its source and sink fluxes. J Lake Sci, 2004, 16(1) : 10-20. DOI: 10.18307/2004.0102. [范成新, 张路, 秦伯强等. 太湖沉积物-水界面生源要素迁移机 制及定量化—1. 铵态氮释放速率的空间差异及源-汇通量. 湖泊科学, 2004, 16 (1) : 10-20.]

[56] Wang JJ, Shen J, Zhang L et al. Sediment-water nutrient fluxes and the effects of oxygen in Lake Dianchi and Lake Fuxian, Yunnan Province. J Lake Sci, 2010, 22(5) : 640-648. DOI: 10.18307/2010.0503. [王建军, 沈吉, 张路等. 云南 滇池和抚仙湖沉积物-水界面营养盐通量及氧气对其的影响. 湖泊科学, 2010, 22(5): 640-648.]

[57] Li B. Study on the process of sediment-water interface and the simulation of endogenous control effect in the restoration of dianchi lake bay[Dissertation]. Nanjing: Nanjing Institute of Geography and Limnology, Chinese Academic of Sciences, 2008. [李宝. 滇池湖湾修复中底泥-水界面过程研究及内源控制效应模拟 [ 学位论文]. 南京: 中国科学院南京地 理与湖泊研究所, 2008.]

[58] Liu C, Zhong J, Wang J et al. Fifteen-year study of environmental dredging effect on variation of nitrogen and phosphorus exchange across the sediment-water interface of an urban lake. Environmental Pollution, 2016, 219: 639-648.

[59] Zhang L, Fan CX, Wang JJ et al. Space-time dependent variances of ammonia and phosphorus flux on sediment-water interface in Lake Taihu. Environmental Science, 2006, 27(8): 1537-1543. [张路, 范成新, 王建军等. 太湖水土界面氮 磷交换通量的时空差异. 环境科学, 2006, 27 (8) : 1537-1543.] 